\title{
PENGEMBANGAN MEDIA PEMBELAJARAN INTERAKTIF BERBASIS POWERPOINT DI SEKOLAH DASAR
}

\author{
Santosa Wijayanto ${ }^{1}$ \\ Petrus Sianggian Purba ${ }^{2 *}$ \\ Ghema Nusa Persada ${ }^{3}$ \\ Rian Purnama 4 \\ Ade Suhendar 5 \\ Usman 6 \\ 1,2,3,4,5,6 Universitas Pamulang, Banten, Indonesia \\ dosen02684@unpam.ac.id ${ }^{1)}$ \\ dosen02684@unpam.ac.id ${ }^{*}$ ) \\ dosen02684@unpam.ac.id ${ }^{3}$ \\ dosen02684@unpam.ac.id ${ }^{4}$ \\ dosen02684@unpam.ac.id ${ }^{5}$ \\ dosen02684@unpam.ac.id6)
}

Kata Kunci: [Media

Digital, Interaktif,

Powerpoint]

Published by:

\begin{abstract}
Abstrak: Salah satu faktor rendahnya mutu pendidikan disebabkan oleh proses pembelajaran yang masih sederhana dengan menggunakan media yang tidak bervariatif. Selain itu belum diterapkanya media pembelajaran yang dapat meningkatkan penyerapan informasi dalam ingatan dengan baik. Salah satu cara untuk menyimpan informasi didalam ingatan diperlukan media pembelajaran yang tepat. Dimana cendrung selama ini proses belajar yang tidak menggunakan media yang bervariatif, sehingga masih terdapat beberapa guru yang menggunakan metode ceramah sehingga berpengaruh terhadap rendahnya kemamupuan siswa untuk mengingat dan memahami materi. Media pembelajaran powerpoint dirasa sangat tepat untuk mengatasi hal tesebut, karena media ini memberikan informasi secara audiovisual sehingga siswa dapat menyerap informasi dengan melihat, mendengar, dan merespon, dengan kemampuan mengingat siswa masing-masing pesan informasi secara visual mudah dipahami oleh siswa, lebih merangsang siswa untuk mengetahui lebih jauh tentang bahan ajar yang sedang disajikan, objek yang ditampilkan terlihat kongkrit (nyata). Penyajian powerpoint yang bervariatif karena terdapat aplikasi gambar, animasi, sound, video sehingga membuat proses belajar tidak menjenuhkan.
\end{abstract}

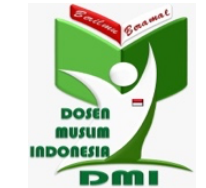

Copyright (C) 2021 The Author(s)

This article is licensed under CC BY 4.0 License

(cc) BY

https://dmi-journals.org/jai/ 


\section{Pendahuluan}

Perkembanagan teknologi informasi dewasa ini telah berimbas pada dunia pendidikan, dengan ditandai oleh munculnya berbagai inovasi dan kreasi dalam proses penyampaian bahan ajar kepada peserta didik Sebagaimana kita ketahui, bahwa dalam proses pendidikan terdapat tiga proses inti pendidikan (Core processes) yang meliputi Pengajaran (Teaching), Penelitian (Research), dan Pelayanan (Services), dimana ketiganya menjadi sumber akses bagi penggunaan dan pemanfaatan teknologi informasi. Ada beberapa konsep yang melatar belakangi penggunanaan teknologi informasi untuk kegiatan pendidikan, dan beberapa diantara sudah banyak diterapkan di lembaga pendidikan baik tingkat dasar maupun tingkat menengah, apalagi di perguruan tinggi. Penggunanaan teknologi ini telah berdampak langsung dan tidak langsung terhadap cara penyelenggaraan pendidikan yang mengarah pada peningkatan mutu sumberdaya manusia.

Istilah media berasal dari bahasa Latin yang merupakan bentuk jamak dari "medium" yang secara harafiah berarti perantara atau pengantar. Media dapat diartikan sebagai alat bantu apa saja yang dapat dijadikan sebagai penyalur pesan guna mencapai tujuan pembelajaran. Selanjutnya ditegaskan media adalah segala sesuatu yang dapat digunakan untuk menyalurkan pesan dari pengirim ke penerima sehingga dapat merangsang pikiran, perasaan, perhatian dan minat siswa sedemikian rupa sehingga terjadi proses belajar

Microsoft PowerPoint merupakan sebuah software yang dibuat dan dikembangkan oleh perusahaan Microsoft, dan merupakan salah satu program berbasis multi media. Didalam komputer, biasanya program ini sudah dikelompokkan dalam program Microsoft Office. Program ini dirancang khusus untuk menyampaikan presentasi, baik yang diselenggarakan oleh perusahaan, pemerintahan, pendidikan, maupun perorangan, dengan berbagai fitur menu yang mampu menjadikannya sebagai media komunikasi yang menarik. Program ini selain digunakan sebagai media dalam presentasi, juga dapat digunakan dalam berbagai macam kegiatan lainnya karena media ini menyediakan berbagai fasilitas untuk berkreasi, mengolah, dan menginputfile audio maupun visual. Keterbatasannya di dalam berkreasi dan mengolah audiovisual dapat diselesaikan dengan mengintegrasikan dengan program-program lain. Hasil kreasi dan olahan dariprogram lain kemudian di-input ke dalam program ini untuk diolah dan dipresentasikan.

\section{Metode Pelaksanaan}

Pengabdian Kepada Masyarakat (PKM) bertujuan untuk membantu masyarakat dalam proses pemberdayaan/pengembangan diri dalam rangka mencapai perikehidupan yang lebih maju, adil, dan sejahtera. Termasuk di dalamnya adalah usaha untuk meningkatkan kemampuan para Guru dan Tenaga Pengajar di SD NEGERI BABAKAN 01.

Dalam pelaksanaan Pengabdian Kepada Masyarakat (PKM) yang akan dilaksanakan di SD NEGERI BABAKAN 01 terdapat beberapa tujuan yang ingin dicapai, diantaranya: 
1. Membuat Bahan ajar yang Interaktif dan disukai para siswa bagi para Guru dan Tenaga Pengajar

2. Memotivasi Para Guru dan Tenaga Pengajar untuk mampu menggunakan Aplikasi Powerpoint.

3. Menambah kompetensi Guru dan Tenaga Pengajar agar lebih aktif berkreasi sesuai dengan perkembangan zaman.

\section{Hasil dan Pembahasan}

Desain Pemecahan Masalah yang dilakukan pada saat kegiatan pengabdian kepada masyarakat adalah memberikan kemampuan dasar dan teknik pembuatan bahan ajar kepada para Guru dan Tenaga pengajar Berikut ini adalah desain pemecahan masalah pada obyek PKM, yaitu:

1. Pengenalan Power point.

2. Keuntungan menggunakan Power point.

3. Manfaat menggunakan Power point untuk guru dan siswa.

4. Pelatihan dan panduan.

5. Kesimpulan Materi.

6. Penutup

Pelaksanaan pengembangan media pembelajaran interaktif berbasis power point dilaksanakan di SD NEGERI BABAKAN 01. Pelaksanaan kegiatan berupa pemaparan materi yang akan diangkat lalu sesi tanya jawab. Adapun susunan kegiatan pelaksanaan acaranya adalah sebagai berikut : Berikut adalah susunan acara PKM yang telah dilaksanakan (Lihat Tabel 1):

Tabel 1. Pelaksanaan Kegiatan PKM

\begin{tabular}{|c|c|c|c|}
\hline No. & Rundown & Acara & Penanggung Jawab \\
\hline 1 & $13.00-13.10$ & Pembukaan Oleh MC & Usman \\
\hline 2 & $13.10-13.20$ & Sambutan ketua PKM & $\begin{array}{l}\text { Santosa Wijayanto, S.T, } \\
\text { M.Kom }\end{array}$ \\
\hline 3 & $13.20-13.30$ & $\begin{array}{l}\text { Sambutan kepala } \\
\text { sekolah }\end{array}$ & N. Dewi Suryawato, S.Pd, Ni \\
\hline 4 & $13.30-14.10$ & $\begin{array}{l}\text { Penyampaian Materi } \\
\text { /Praktek }\end{array}$ & Ade Suhendar \\
\hline 6 & $14.10-14.20$ & $\begin{array}{l}\text { Penyimpulan Materi } \\
\text { Akhir }\end{array}$ & Petrus Sianggian P, M.kom \\
\hline 7 & $14.20-14.30$ & Tanya Jawab/Kuis & Petrus Sianggian P, M.kom \\
\hline 8 & $14.30-14.40$ & Penutup Acara/Do'a & $\begin{array}{l}\text { Ghema Nusa } \\
\text { Persada,S.Kom,M.TI }\end{array}$ \\
\hline 9 & $14.40-14.45$ & $\begin{array}{l}\text { Penyerahan } \\
\text { Plakat/Souvenir }\end{array}$ & $\begin{array}{l}\text { Santosa Wijayanto, S.T, } \\
\text { M.Kom }\end{array}$ \\
\hline 10 & $14.45-14.55$ & Dokumentasi & Kelompok \\
\hline
\end{tabular}

\section{Penyampaian Materi}

Materi "Pengembangan Media Pembelajaran Interaktif Berbasis Power Point di Sekolah Dasar" dilakukan dengan metode presentasi langsung/offline. Materi yang 
disampaikan meliputi pembuatan bahan ajar yang interaktif dan menyenangkan siswa dengan Microsoft Powerpoint bagi para Guru dan Tenaga Pengajar.

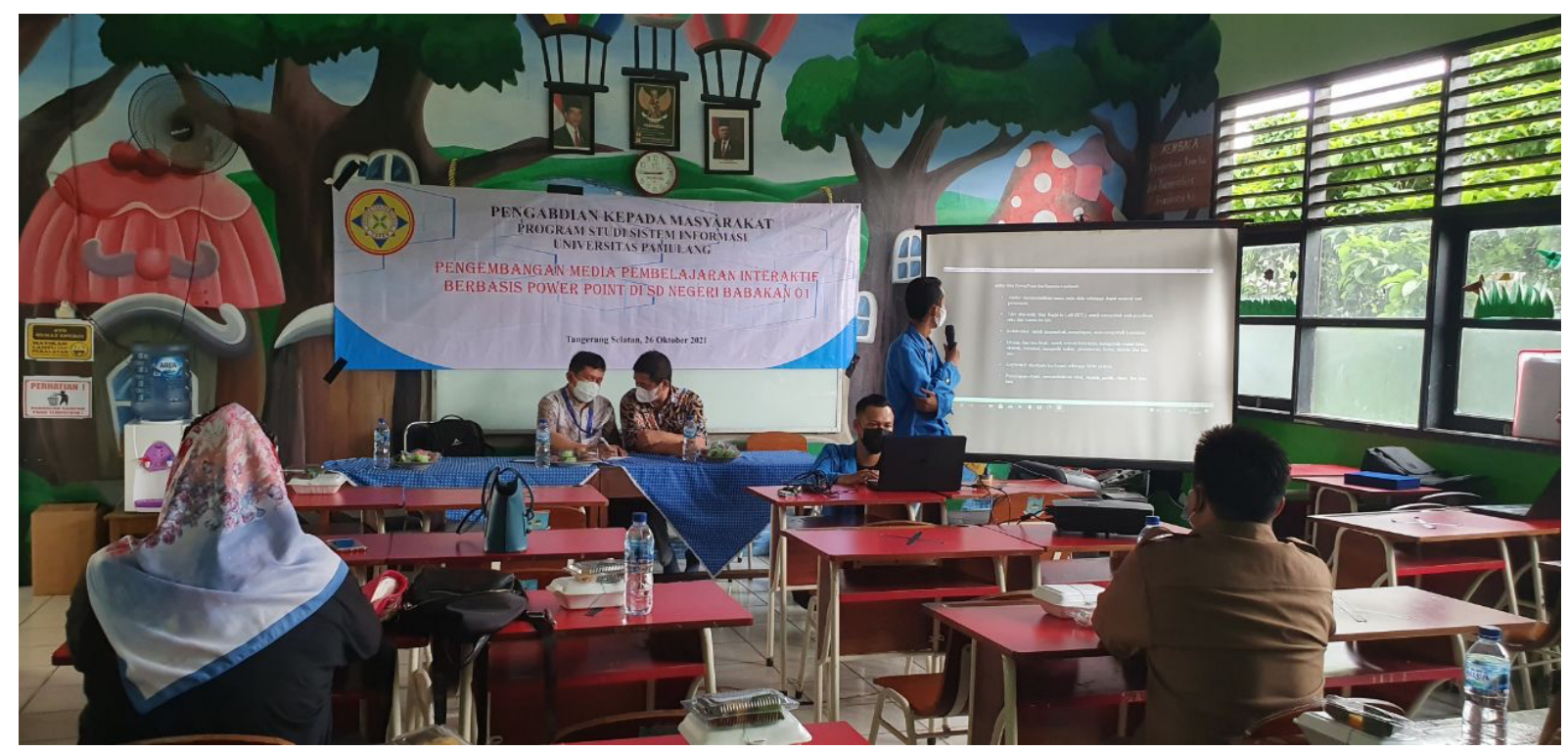

Gambar 1. Penyampaian Materi

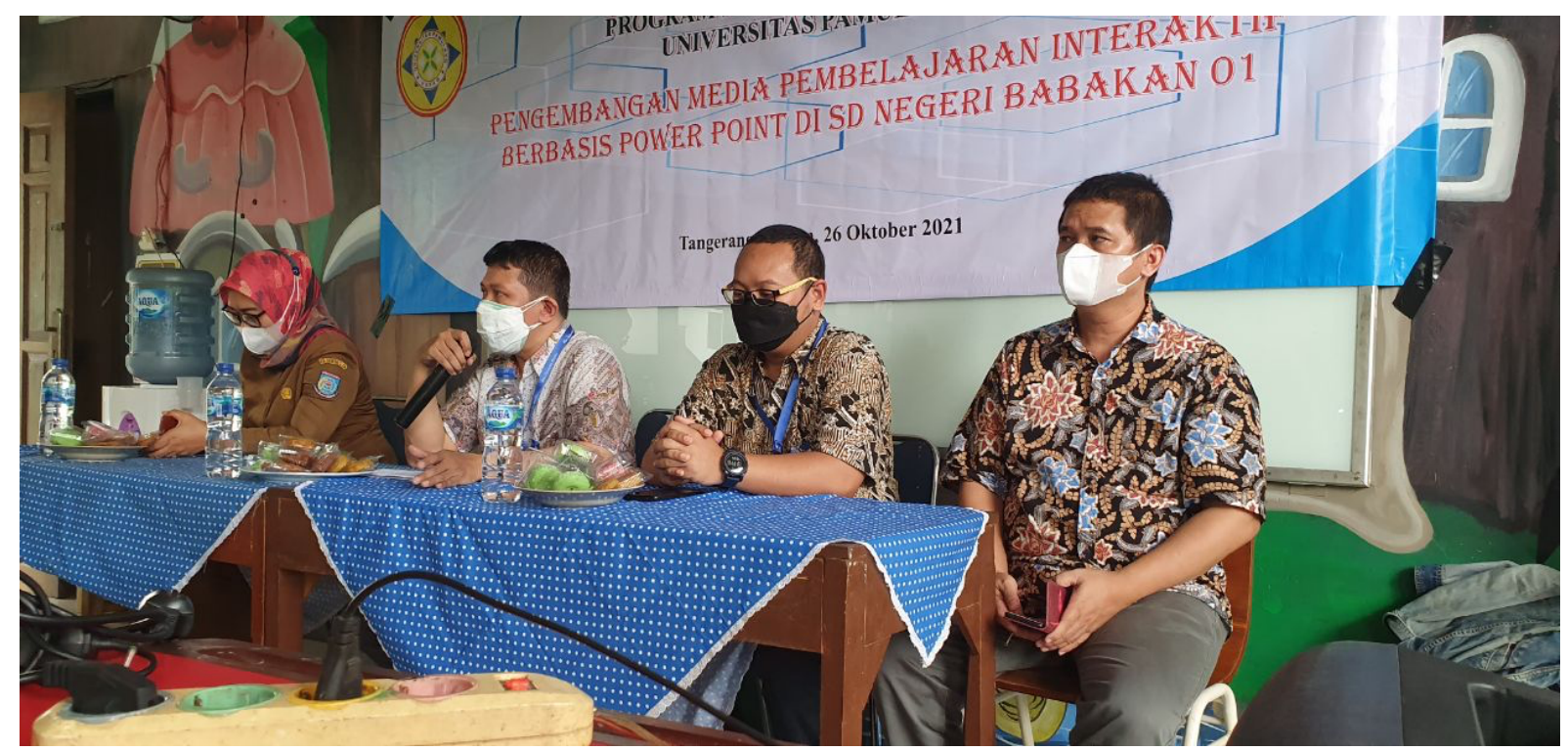

Gambar 2. Diskusi Materi

\section{Demo Implementasi Pembelajaran Interaktif}

Peserta diberikan arahan langsung secara step-by-step tentang bagaimana cara menggunakan Power Point sebagai media pembelajaran interaktif. 


\section{Jurnal Abdimas Indonesia}

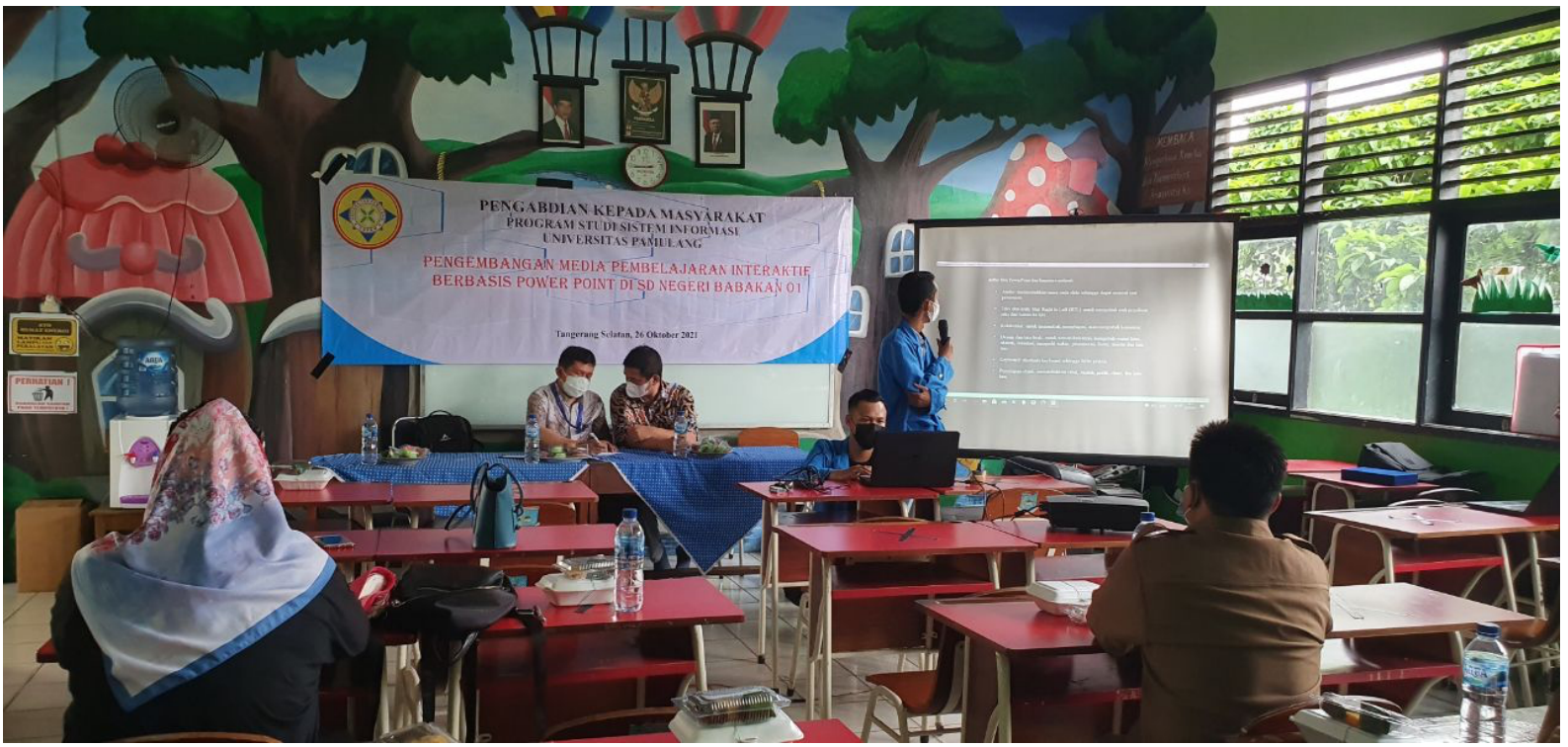

Gambar 3. Sesi 2 Penyampai Materi

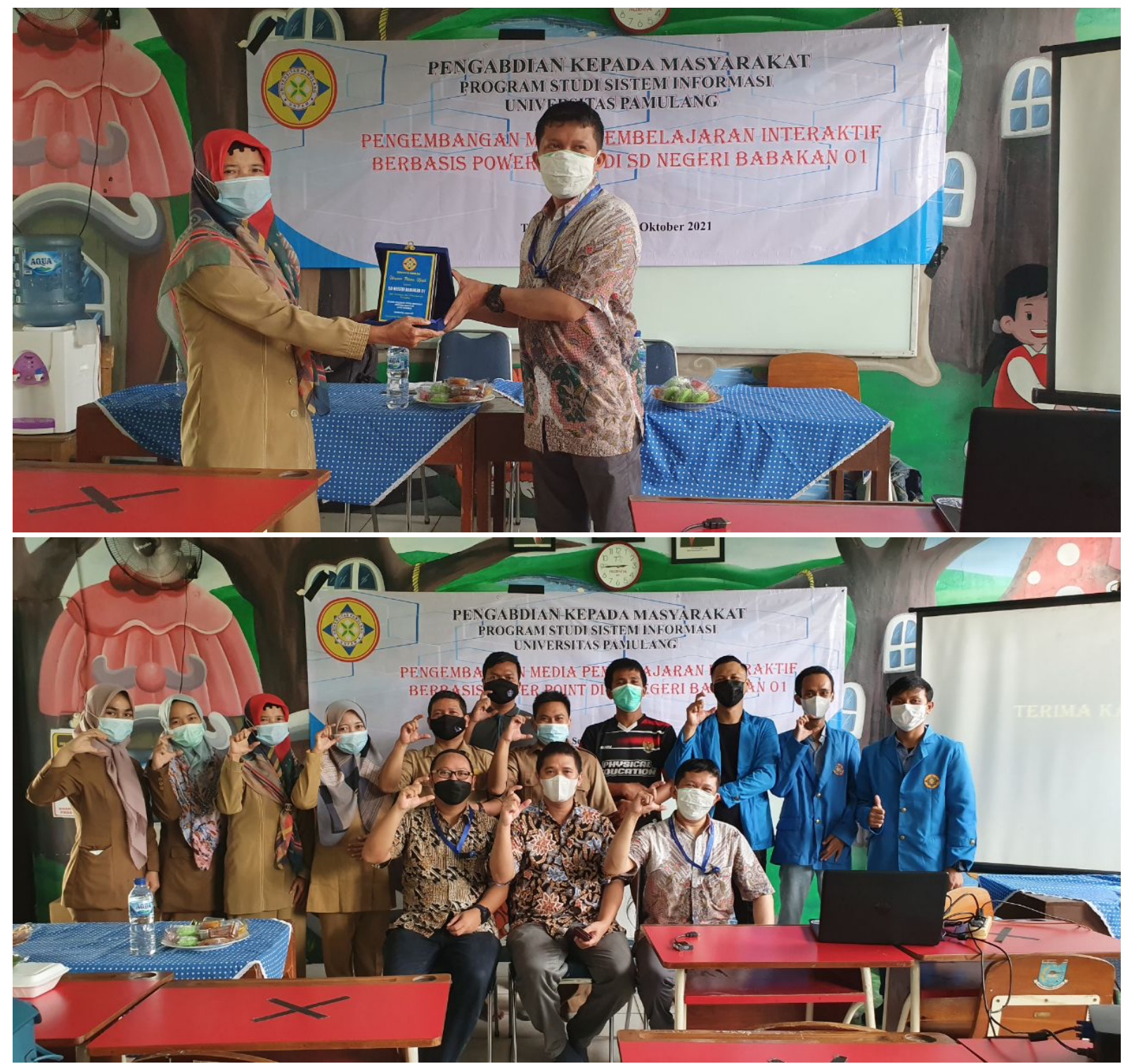

Gambar 5. Dokumentasi penyerahan plakat dan foto bersama 
Kegiatan pengabdian kepada masyarakat diharapkan dapat memberikan manfaat terutama pada masyarakat yang dilakukan oleh Tim Fakultas Teknik Sistem Informasi Universitas Pamulang. Dari hasil kegiatan pengabdian kepada masyarakat ini, dapat disimpulkan beberapa hal sesuai tujuan dari pengabdian di SD NEGERI BABAKAN 01 yang nantinya di harapkan para guru dapat memanfaatkan teknologi dalam proses pembelajaran, sehingga menjadi lebih menarik terhadap perserta didik. Disamping itu kegiatan ini juga dapat menambah pengetahuan bagi mahasiswa untuk melatih menggunakan ilmu yang telah didapat selama perkuliahan.

\section{Kesimpulan} bahwa:

Dari kegiatan Pengabdian Kepada Masyarakat ini dapat diambil kesimpulan

1. Para Tenaga Pengajar SD NEGERI BABAKAN 01 sudah mengetahui pengunaan aplikasi Microsoft PowerPoint tapi masih terbatas hal hal yang umum.

2. Bahan ajar dan media ajar kepada siswa dapat di buat lebih interaktif dan kreatif dan menyenangkan siswa dengan menggunakan fitur-fitur yang terdapat pada aplikasi Microsoft Powerpoint.

3. Untuk memastikan bahwa media yang tenaga pengajar gunakan adalah yang paling relevan dan terbaik, tenaga pengajar perlu membiasakan diri untuk terus mencari informasi mengenai perkembangan teknologi informasi.

4. Maka dari itu mahasiswa Sarjana Komputer Universitas Pamulang diharapkan dapat berupaya melakukan kontribusi dalam melaksanakan kegiatan pengabdian kepada masyarakat.

\section{Ucapan Terimakasih} kepada:

Penulis dengan segala kerendahan hati menyampaikan ucapan terima kasih

1. Bapak Dr. H. E. Nurzaman, AM., M.M., M.Si. selaku Rektor Universitas Pamulang.

2. Bapak Dede Supriyadi, S.Kom., M.Kom. selaku Ketua Prodi Sistem Informasi S1 Universitas Pamulang.

3. Bapak Dr. Ali Maddiansyah, S.E., M.M. selaku Kepala LPPM Universitas Pamulang.

4. Bapak Dr. Yunus, S.Pd.I., M.Pd.I. selaku Koordinator LPPM Prodi Sistem Informasi Universitas Pamulang.

5. Bapak Salman Farizy, S.Kom., MCSE, MVP. selaku Dosen mata kuliah Kerja Praktek.

6. Bapak Petrus S.P, M.Kom, Bapak Ghema Nusa Persada, S.Kom, M.TI dan Bapak Santosa Wijayanto, S.T., M.Kom. selaku Dosen Pembimbing.

7. Rekan-rekan mahasiswa Program Studi Sistem Informasi Universitas Pamulang.

\section{Referensi}

Rusman, dkk. 2013. Pembelajaran Berbasis Teknologi Informasi dan Komunikasi. Jakarta: Rajawali Pers.

Sukiman. 2011. Pengembangan Media Pembelajaran. Yogyakarta: Pustaka Insan Madani. 
Azhar Arsyad. 2013. Media Pembelajaran. Jakarta: Rajagrafindo Persada.

Ahmad Susanto. 2014. Teori Belajar dan Pembelajaran di Sekolah Dasar, (Jakarta: Kencana Prenada Media Group)

Sanjaya, Wina. 2012. Strategi Pembelajaran Berorientasi Standar Proses Pendidikan.Jakarta: Kencana

Azhar Arsyad. 2013. Media Pembelajaran. Jakarta: Rajagrafindo Persada.

Daryanto. (2016). Media Pembelajaran. Yogyakarta: Gava Media. 